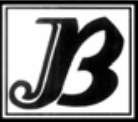

J. bio-sci. 14: 43-48, 2006

ISSN 1023-8654

\title{
TOXICITY OF ESSENTIAL OILS AGAINST RED FLOUR BEETLE, TRIBOLIUM CASTANEUM (HERBST) (COLEOPTERA: TENEBRIONIDAE)
}

\author{
Mina Mondal and M Khalequzzaman* \\ Department of Zoology, Rajshahi University, Rajshahi, Bangladesh
}

\begin{abstract}
Contact and fumigant toxicity of the three essential oils, viz., cardamom (Elletaria cardamomum Maton), Cinnamon (Cinnamomum aromaticum Nees), and Clove (Syzygium aromaticum (L.) Merr. and Petry) were tested against the red flour beetle, Tribolium castaneum (Herbst) larvae and adults. Residual film bioassay was employed in Petri dish $(5 \mathrm{~cm}$ dia.) for contact toxicity studies and $6 \mathrm{~cm} \times 1.8 \mathrm{~cm}$ glass vials were used for testing fumigation actions. Three day old adults and 10- day old larvae were equally susceptible to the contact toxicity of cinnamon oil, with $L D_{50}$ values of 0.074 and $0.196 \mathrm{mg} \mathrm{cm}^{-2}$ respectively. Cardamom oil provided higher toxicity to 14 -day and 18 - day old larvae having $L_{50}$ value of $0.10 \mathrm{mg} \mathrm{cm}^{-2}$. In fumigation bioassay cinnamon oil provided the highest toxicity to adult and 10-, 14-, and 18-day old larvae, with $L_{50}$ values of $0.03,0.05,0.088$ and $0.09 \mathrm{mg} \mathrm{cm}^{-3}$ respectively. Furthermore, 10-day old larvae were more tolerant than the adults to the contact toxicity of the essential oils, but 14- day old larvae had the same susceptibility as the adults. In contact and fumigation toxicity adults and all stages of larvae were more resistant to clove oil.
\end{abstract}

Key words: Bioassay, cardamom, cinnamon, clove, toxicity, essential oil.

\section{Introduction}

The red flour beetle, Tribolium castaneum (Herbst) is one of the major pests of stored grains and grain products in the tropics. The control of this insect relies heavily on the use of synthetic insecticides and fumigants, which has led to problems such as disturbances of the environment, increasing costs of application, pest resurgence, pest resistance to pesticides and lethal effects on non-target organisms in addition to direct toxicity to users. An alternative to synthetic pesticides is the use of natural compounds, "such as essential oils that result from secondary metabolism in plants. The toxicity of a large number of essential oils and their constituents have been evaluated against a number of stored-product insects (Paranagama et al. 2003).

Essential oils are commercially used in four primary aspects: as aromas in fragrances and perfumes, as flavouring food additives, as pharmaceuticals, and as insecticides. They recently have received much attention due to their multi-functions as antimicrobial, antifungal, antitumor and insecticidal agents (de Souza et al. 2005). Essential oils and especially their main compounds monoterpenoids, offer promising alternatives to classical fumigants (Peterson and Ems-Wilson 2003, Aslan et al. 2004). Essential oils are volatile and can act like fumigants offering the prospect for use in stored-product protection (Lee et al. 2001, 2002a,b, 2004), contact insecticides (Tapondjou et al. 2002, Peterson and Ems-Wilson 2003), antifeedent or repellent effects (Kim et al. 2003a,b, Park et al. 2003a,b, García et al. 2005) and may also affect some biological parameters such as growth rate, life span and reproduction (Tunç et al. 2000, Kathuria and Kaushik 2005, Rahmat et al. 2006).

"Corresponding author. E-mail: kzaman@ru.ac.bd. 
In the present experiment three essential oils, e.g. cardamom, Elletaria cardamomum (L.), cinnamon (Cinnamomum aromaticum Nees) and clove (Syzygium aromaticum L. Meer and Perry) were tested in a series of toxicological experiments in order to determine their contact and fumigant effects on $T$. castaneum.

\section{Materials and Methods}

\section{Biological materials}

T. castaneum were used in this study. All larvae and adults were obtained from laboratory cultures maintained in the incubators at $30 \pm 1^{\circ} \mathrm{C}$ and $70 \pm 5 \%$ r.h at dark. The beetles were reared on wheat flour mixed with yeast (10:1 w:w). The larvae of $T$. castaneum used in contact and fumigant toxicity experiments were 10-, 14- and 18- days old and adults were three to four days post-eclosion. All essential oils were procured from the pharmacy as of $90 \%$ purity and were further purified in the rotary evaporator in the Crop protection and Toxicology Laboratory, Department of Zoology, Rajshahi University.

\section{Contact Bioassay}

Series of dilutions of essential oils were prepared using acetone as a solvent. Aliquots of $1 \mathrm{ml}$ of the dilutions were applied into $6 \mathrm{~cm}$ dia. petridishes for surface-film bioassay (Busvine 1971). The solvent was allowed to evaporate for 1 hour and the treated insects were transferred to petridishes. Controls were treated with acetone alone. Fifteen adults or larvae of the species were used for each concentration and 20 adults or larvae were used for control. The petridishes were kept in the incubator and mortality was observed after $24 \mathrm{~h}$.

\section{Fumigant bioassay}

Series of dilutions of essential oils were prepared using acetone as a solvent. Glass vials $(6 \mathrm{~cm}$ long, $1.8 \mathrm{~cm}$ dia.) capped with polypropylene stoppers were used for the bioassays. Adult or larvae were transferred to the vials in groups of ten individuals and the vials were covered with fine nylon cloth secured with adhesive tape. Aliquots of $0.05 \mathrm{ml}$ of the dilution were placed into similar vials. After evaporating the solvent, the vials containing the insects were turned upside down over the vials containing the oil so that the oil vapours saturated the atmosphere of the vials containing the beetles. Four replications of each treatment were set up. Controls were maintained in the similar way with the solvent only. The vials were kept in the incubator and mortality was observed after $24 \mathrm{~h}$ pose-exposure.

\section{Data analysis}

Mortality data were corrected using Abbott's formula (Abbott 1925). The observed data were subjected to probit analysis according to Finney (1947) and Busvine (1971) using a software developed at the Department of Agricultural and Environmental Science, University of Newcastle Upon Tyne, U K.

\section{Results}

In surface-film bioassay cinnamon oil offered the highest toxicity to adults and 10- day old larvae, whereas cardamom oil provided the maximum toxicity to 14- and 18- day old larvae. Cinnamon oil vapour (by fumigation) caused the highest mortality of various life stages of $T$. castaneum at $L D_{50}$ level (Table 1). The adult were more susceptible than larvae to contact and fumigant actions. As the larvae grew older, they became less susceptible. Among the three essential oils clove oil was less toxic to $T$. castaneum to the contact and fumigation actions. In contrast to contact toxicity, adults were susceptible to the fumigant toxicity of all the three essential oils, and they were more susceptible than larvae. 
Table 1. Contact and fumigant toxicity of some essential oils against Tribolium castaneum larvae and adults.

\begin{tabular}{|c|c|c|c|c|c|c|}
\hline \multirow[b]{2}{*}{ Oil } & \multirow[b]{2}{*}{ Life stage } & \multirow{2}{*}{$\begin{array}{c}\text { Dose } \mathrm{LD}_{50}(\mathrm{mg} \\
\left.\mathrm{cm}^{-2}\right)\end{array}$} & \multicolumn{2}{|c|}{$95 \%$ confidence limits } & \multirow[b]{2}{*}{ Regression equation } & \multirow[b]{2}{*}{$\chi^{2}(2 d f)$} \\
\hline & & & $\begin{array}{c}\text { Lower (mg } \\
\left.\mathrm{cm}^{-2}\right)\end{array}$ & $\begin{array}{c}\text { Upper (mg } \\
\left.\mathrm{cm}^{-2}\right)\end{array}$ & & \\
\hline \multicolumn{7}{|c|}{ Surface-film bioassay } \\
\hline \multirow{4}{*}{ Cardamom } & $\begin{array}{l}\text { Adult } \\
\text { Larval age }\end{array}$ & 0.122 & 0.092 & 0.160 & $Y=3.465192+1.414348 X$ & 0.151 \\
\hline & 10 day & 0.294 & 0.193 & 0.450 & $Y=3.690108+0.891879 X$ & 0.202 \\
\hline & 14 day & 0.101 & 0.072 & 0.142 & $Y=3.775373+1.218838 X$ & 0.446 \\
\hline & 18 day & 0.092 & 0.062 & 0.136 & $Y=3.924968+1.116663 X$ & 0.039 \\
\hline \multirow{4}{*}{ CInnamon } & Adult & 0.074 & 0.051 & 0.106 & $Y=3.938027+1.22351 X$ & 0.538 \\
\hline & 10 day & 0.196 & 0.138 & 0.280 & $Y=3.574011+1.102561 X$ & 0.140 \\
\hline & 14 day & 0.108 & 0.075 & 0.154 & $Y=3.902944+1.06257 X$ & 0.287 \\
\hline & 18 day & 0.235 & 0.133 & 0.417 & $Y=3.861711+0.82974 X$ & 0.888 \\
\hline \multirow{4}{*}{ Clove } & $\begin{array}{l}\text { Adult } \\
\text { Larval age }\end{array}$ & 0.341 & 0.269 & 0.433 & $Y=4.137235+1.618698 X$ & 0.434 \\
\hline & & 1.134 & 0.496 & 2.592 & $Y=4.075463+0.87668 X$ & 0.139 \\
\hline & 10 day & 0.922 & 0.386 & 2.199 & $Y=4.296858+0.728981 X$ & 0.808 \\
\hline & $\begin{array}{l}14 \text { day } \\
18 \text { day }\end{array}$ & 0.779 & 0.392 & 1.549 & $Y=4.261798+0.82794 X$ & 2.238 \\
\hline \multicolumn{7}{|c|}{ Fumigation bioassay } \\
\hline \multirow{4}{*}{ Cardamom } & Adult & 0.223 & 0.150 & 0.332 & $Y=3.376679+1.203566 X$ & 1.853 \\
\hline & $\begin{array}{l}\text { Larval age } \\
10 \text { day }\end{array}$ & 0.346 & 0.206 & 0.582 & $Y=3.598921+0.910077 X$ & 0.189 \\
\hline & 14 day & 0.355 & 0.252 & 0.499 & $Y=2.80085+1.419142 X$ & 0.662 \\
\hline & 18 day & 0.348 & 0.243 & 0.497 & $Y=2.933418+1.340766 \mathrm{X}$ & 0.198 \\
\hline \multirow{4}{*}{ CInnamon } & $\begin{array}{l}\text { Adult } \\
\text { Larval age }\end{array}$ & 0.030 & 0.017 & 0.052 & $Y=4.428527+1.204901 X$ & 0.928 \\
\hline & 10 day & 0.050 & 0.030 & 0.084 & $Y=4.325145+0.960671 X$ & 0.090 \\
\hline & 14 day & 0.088 & 0.048 & 0.160 & $Y=4.262812+0.781603 X$ & 0.065 \\
\hline & 18 day & 0.090 & 0.060 & 0.133 & $Y=3.844475+1.213423 X$ & 0.660 \\
\hline \multirow{4}{*}{ Clove } & $\begin{array}{l}\text { Adult } \\
\text { Larval age }\end{array}$ & 0.120 & 0.080 & 0.180 & $Y=3.762674+1.145967 X$ & 0.246 \\
\hline & 10 day & 0.214 & 0.101 & 0.452 & $Y=3.986094+0.76256 X$ & 0.333 \\
\hline & 14 day & 0.163 & 0.091 & 0.289 & $Y=3.963585+0.85587 X$ & 0.258 \\
\hline & 18 day & 0.131 & 0.082 & 0.207 & $Y=3.88088+1.002968 X$ & 0.251 \\
\hline
\end{tabular}

\section{Discussion}

Cardamom oil was generally a more effective contact poison and fumigant against the adults of $T$. castaneum. These findings are similar to those of nutmeg oil (Huang et al. 1997). The essential oil of garlic was more toxic to $T$. castaneum than to $S$. zeamais by contact (Ho et al. 1996), while cinnamaldehyde, the 
main constituent of cinnamon oil, exerted equal contact toxicity to both $T$. castaneum and Sitophilus zeamais (Huang and Ho 1998). T. castaneum adults showed similar susceptibility to the contact of cinnamaldehyde, having an $\mathrm{LC}_{50}$ of $0.7 \mathrm{mg} \mathrm{cm}^{-2}$. However, it had higher fumigant toxicity with an $\mathrm{LC}_{50}$ of $0.28 \mathrm{mg} \mathrm{cm}^{-2}$. The larvae became less susceptible to both contact and fumigant toxicity of cinnamaldehyde with age (Huang and Ho 1998). Contact toxicities of cardamom oil were tested by Huang et al. (2000). They observed that adults of $S$. zeamais and $T$. castaneum were equally susceptible to the contact toxicity of the cardamom oil at the $\mathrm{LD}_{50}$ values of 56 and $52 \mathrm{mg} \mathrm{mg}^{-1}$ insect respectively. Furthermore, 12-day old larvae of $T$. castaneum were more tolerant than the adults to the contact toxicity of the oil, but 14- and 16-day old larvae had the same susceptibility as the adults.

The essential oil of garlic (Ho et al. 1996) as well as the n-hexane extract of star anise (Ho et al. 1995) and its main constituent, anethole (Ho et al. 1997) were more toxic to T. castaneum. On the other hand, the nhexane extract of clove flower buds (Ho et al. 1994) and its main constituent, eugenol were more toxic to $T$. castaneum and $S$. zeamais. Cinnamaldehyde is a more potent insecticide against $T$. castaneum than anethole and eugenol. Therefore, cinnamaldehyde is more advantageous as a contact poison as it is equally effective against both species of insects. The larvae of $T$. castaneum were progressively more tolerant to cinnamaldehyde with age, a trend similarly observed with the hexane extracts of clove (Ho et al. 1994) and star anise (Ho et al. 1995) as well as the essential oil of garlic (Ho et al. 1996). As in the case of contact toxicity, a similar trend was observed in the fumigant toxicity test to $T$. castaneum larvae, and the larvae became less susceptible to cinnamaldehyde with age.

A direct comparison of the potency of contact toxicities of the essential oils could not be made because different experimental methods were employed. These studies suggest that cardamom oil may be a potential grain protectant by killing various life stages of $T$. castaneum through contact and fumigant actions. This study suggests that cinnamon, cardamom and clove could be potent grain protectants due to their contact and fumigant activities against the $T$. castanium. The advantages of using essential oils as a grain protectants are: (1) they can be easily extracted by steam distillation; (2) they have very low toxicity to mammals since the popular spices consumed by people in various parts of the world; and (3) the essential oils are volatile and this can be potentially used fumigants.

\section{References}

Abbott W S (1925) A method of computing the effectiveness of an insecticide. J. Econ. Entomol. 18: 265-267.

Aslan İ, Özbek H, Çalmaşur Ö and Şahin F (2004) Toxicity of essential oil vapours to two greenhouse pests, Tetranychus urticae Koch and Bemisia tabaci Genn. Indust. Crops Prod. 19: 167-173.

Busvine J R (1971) A Critical Review of the Techniques for Testing Insecticides. Commonwealth Agricultural Bureau, London. $345 \mathrm{pp}$.

de Souza E L, Lima E O, de Luna K R, Freire K R L and de Sousa C P (2005) Inhibitory action of some essential oils and phytochemicals on the growth of various moulds isolated from foods. Brazilian Arch. Biol. Technol. 48(2): 245-250.

Finney D J (1947) Probit Analysis. Cambridge University Press, London. 333 pp.

García M, Donadel O J, Ardanaz C E, Tonn C E and Sosa M E (2005) Toxic and repellent effects of Baccharis salicifolia essential oil on Tribolium castaneum. Pest Manage. Sci. 61: 612-618. 
Ho S H, Cheng L P L, Sim K Y and Tan H T W (1994) Potential of cloves (Syzygium aromaticum (L.) Merr. and Perry as a grain protectant against Tribolium castaneum (Herbst) and Sitophilus zeamais Motsch. Postharvest Biol. Technol. 4: 179-183.

Ho S H, Koh L, Ma Y, Huang Y and Sim K Y (1996) The oil of garlic, Allium satiuum L. (Amaryllidaceae), as a potential grain protectant against Tribolium castaneum (Herbst) and Sitophilus zeamais Motsch. Postharvest Biol. Technol. 9: $41-48$.

Ho S H, Ma Y and Huang Y (1997) Anethole, a potential insecticide from Illicium verum Hook F. against two stored product insects. Int. Pest Contr. 39 (2): 50-51.

Ho S H, Ma Y, Goh P M and Sim K Y (1995) Star anise, Illicium uerum Hook f. as a potential grain protectant against Tribolium castaneum (Herbst) and Sitophilus reamais Motsch. Postharvest Biol. Technol. 6: 341-347

Huang Y and Ho S H (1998) Toxicity and antifeedant activities of cinnamaldehyde against the grain storage insects, Tribolium castaneum (Herbst) and Sitophilus zeamais Motsch. J. stored Prod. Res. 34(1): 11-17.

Huang Y, Lam S L and Ho S H (2000) Bioactivities of essential oils from Elletaria cardamomum (L.) to Sitophilus zeamais Motschulsky and Tribolium castaneum (Herbst). J. stored Prod. Res. 36: 107-117.

Huang Y, Tan J M W L, Kini R M and Ho S H (1997) Toxic and antifeedant action of nutmeg oil against monoterpenes on Acanthoscelides obtectus (Say) (Coleoptera), a bruchid of kidney bean (Phaseolus vulgaris L.). J. stored Prod. Res. 31: 291-299

Kathuria V and Kaushik T (2005) Feeding inhibition of Helicoverpa armigera (Hübner) by Eucalyptus camaldulensis and Tylophora indica extracts. Insect Sci. 12: 249-254.

Kim S I, Park C, Ohh M H, Cho H C and Ahn Y J (2003a) Contact and fumigant activities of aromatic plant extracts and essential oils against Lasioderma serricorne (Coleoptera: Anobiidae). J. stored Prod. Res. 39(1): 11-19.

Kim S I, Roh J Y, Kim D H, Lee H S and Ahn Y J (2003b) Insecticidal activities of aromatic plant extracts and essential oils against Sitophilus oryzae (L.) and Callosobruchus chinensis (L.). J. stored Prod. Res. 39(3): 293-303.

Lee B H, Annis P C, Tumaalii F and Choi W S (2004) Fumigant toxicity of essential oils from the Myrtaceae family and 1,8-cineole against 3 major stored-grain insects. J. stored Prod. Res. 40: 553-564.

Lee B H, Choi W S, Lee S E and Park B S (2001) Fumigant toxicity of essential oil and their constituent compounds towards the rice weevil, Sitophilus oryzae (L.). Crop Prot. 20: 317-320.

Lee B H, Lee S E, Annis P C, Pratt S J, Part B S and Tumaalii F (2002b) Fumigant toxicity of essential oils and monoterpenes against the red flour beetle, Tribolium castaneum Herbst. J. Asia-Pacific Entomol. 5(2): 237-240.

Lee Y H, Park E K and Lee S E (2002a) Adverse effect of essential oil fumigation on Proisotoma minuta (Collembola: Entomobryoidae). J. Asia-Pacific Entomol. 5(1): 131-133.

Paranagama P A, Abeysekera K H T, Abeywickrama K P and Nugaliyadde L (2003) Fungicidal and anti-aflatoxigenic effects of the essential oil of Cymbopogon citratus (DC.) Stapf. (lemongrass) against Aspergillus flavus Link. isolated from stored rice. Let. App. Microbiol. 36: 1-5.

Park C, Kin S and Ahn Y J (2003a) Insecticidal activity of asarones identified in Acorus gramineus rhizome against three coleopteran stored-product insects. J. stored Prod. Res. 39(3): 333-342. 
Park K, Lee S G, Hoi D H, Park J D and Ahn Y J (2003b) Insecticidal activities of constituents identified in the essential oil from leaves of Chamaecyparis obtuse against Callosobruchus chinensis (L.) and Sitophilus oryzae (L.). J. stored Prod. Res. 39(4): 375-384.

Peterson C J and Ems-Wilson J (2003) Catnip essential oil as a barrier to subterranean termites (Isoptera: Rhinotermitidae) in the laboratory. J. Econ. Entomol. 96(4): 1275-1282.

Rahmat A, Edrini S, Ismail P, Hin T Y Y and Bakar M F A B (2006) Chemical constituents, antioxidant and cytotoxic effects of essential oil from Strobilanthes crispus and Lawsonia inermis. J. Biol. Sci. 6(6): 1005-1010.

Tapondjou L A, Adler C, Bouda, H and Fontem D A (2002) Efficacy of powder and essential oil from Chenopodium ambrosioides leaves as post-harvest grain protectants against six-stored product beetles. J. stored Prod. Res. 38: 395-402.

Tunç I, Berger B M, Erler F and Dağli F (2000) Ovicidal activity of essential oils from five plants against two storedproduct insects. J. stored Prod. Res. 36: 161-168. 